\title{
Health condition and familial factors associated with health-related quality of life in adolescents with congenital heart disease: a cross sectional study
}

Yu-Mi $I m^{1}$, Tae-Jin Yun ${ }^{2}$ and Sunhee Lee ${ }^{3^{*}}$ (1)

\begin{abstract}
Background: The focus of clinical care after the repair of congenital heart disease has shifted from saving life of the patient to the patient's quality of life. The purpose of this study was to examine the health condition and familial factors associated with the health related quality of life of adolescents with congenital heart disease.

Methods: Ninety-eight adolescents aged 13-19 years were collected from a congenital heart clinic from July 22 to August 23, 2013. Perceptions of parental rearing behaviors, health related quality of life of adolescent with congenital heart disease, and general characteristics were measured. We used multiple linear regression analysis to explore factors that are associated with the health related quality of life of adolescents with congenital heart disease.

Results: New York heart association class (Adj $R^{2}=.186, p=.000$ ), presence of siblings (Adj $R^{2}=.240, p=.010$ ), and mother's emotional warmth (Adj $R^{2}=.265, p=.043$ ) were significantly associated with the health related quality of life of adolescents with congenital heart disease.

Conclusions: Emotionally warm parental rearing behaviors and the presence of siblings were important familial factors that were positively associated with HRQOL in adolescents with CHD. Therefore, it is important for healthcare providers to develop a greater sensitivity to, and awareness of, the familial influences that may be impacting a subject's HRQOL, as well as the exigencies of the CHD, itself.
\end{abstract}

Keywords: Siblings, Quality of life, Adolescent, Cardiovascular abnormalities

\section{Background}

Advances in medical and surgical management have improved the life expectancy of children with congenital heart disease (CHD), and have resulted in a significant reduction in mortality [1]. More than $90 \%$ of $\mathrm{CHD}$ patients survive into adulthood in Korea as well as in US $[2,3]$. Due to these increased survival rates, the focus of clinical care after the repair of CHD has shifted from saving the patient's life to the patient's quality of life (QOL). Despite improved life expectancy, uncertainty about the course of illness and prognosis, signs and symptoms of the illness, and restrictions in activity levels

\footnotetext{
* Correspondence: shlee418@catholic.ac.kr

${ }^{3}$ College of Nursing, the Catholic University of Korea, 222 Banpo-daero,

Seocho-gu, Seoul 06591, South Korea

Full list of author information is available at the end of the article
}

nevertheless intrude on patient daily life [4-6]. Some patients also struggle with psychological, educational, or behavioral issues [7]. In addition, many children and adolescents live with morbidities associated with an underlying cardiac lesion and/or its treatment, and such morbidities may impact the health-related QOL (HRQOL) of CHD patients [1]. To date, a lot of studies of the QOL in patients with CHD were conducted, but the results have been inconsistent [8]. Yoon and Lee [9] reported in their study that the QOL of Korean adults with CHD was lower than that of a healthy control group, while Apers et al. reported that the overall QOL in adults with CHD was generally good in their study which covered samples from 15 countries. These inconsistent results indicate that QOL of patients with CHD varies depending on patients' individual experiences [4]. 
HRQOL has been defined as "the specific impact of illness or injury, medical treatment, or health-care policies on an individual's quality of life" [10]. Included in this concept is the individual's perception of the impact of their disease or condition on their physical health status, psychological and social functioning, and emotional well-being, both in terms of their ability to function within these domains and their satisfaction derived from doing so $[10,11]$. Accordingly, HRQOL can be affected by various factors such as health condition, peer group, and family members. Family may be a key predictor of HRQOL for adolescents with disease, because family can provides adolescents with the available information they identify as important [12].

However, only limited research has examined familial and psycho-social factors related with HRQOL for adolescents with CHD. because disease-related condition had a great impact on HRQOL for adolescents with CHD. Therefore, we explored the HRQOL of adolescents with CHD with respect to health condition and familial factors. The objective of the study was to investigate associations between health conditions and familial factors vis-a-vis the HRQOL of adolescents with CHD.

\section{Methods}

\section{Design}

This study was designed as a descriptive study to examine the health condition and familial factors associated with HRQOL for adolescents with CHD.

\section{Data collection and sample}

A total of 103 adolescents aged 13-19 years undergoing follow-up at a pediatric cardiology clinic at a universityaffiliated tertiary medical center in Seoul, South Korea were enrolled in this study. Between July 22 and August 23,2013 , all adolescent patients who visited the pediatric cardiology clinic for follow-up and who met the inclusion criteria were invited to participate in the study. Of these, two patients declined to complete the questionnaire due to time limitations and three patients filled out the questionnaires incompletely; all together, a total of 98 participants were included in the final analysis. Adolescents who had been diagnosed with CHD and have undergone a medical procedure or surgery were included. Adolescents who had a reading disability and insufficient communication skills were excluded. A minimum sample size of 77 was determined by using G-power analysis for F-test, multiple regression analysis with three number of predictors to achieve $80 \%$ power, an alpha $=.05$ and an effect size of 0.15 which is medium size [13]. A research assistant involved with this study explained our questionnaire to participating adolescents and their parents. Following the approval of participants and their families, we obtained self-reported questionnaire results from all subjects. Medical diagnosis was transcribed from the medical record.

\section{Measurements}

Adolescents with CHD completed a self-report questionnaire, which included standardized instruments to measure their perceptions of their mother's and father's parental rearing behaviors, HRQOL, and sociodemographic characteristics. Additionally, participant medical records were reviewed retrospectively in order to obtain health-related factors such as diagnosis.

\section{Parental rearing behaviors (FEE)}

We measured perceptions of parental rearing behaviors in adolescents with $\mathrm{CHD}$ using the Fragebogen zum erinnerten elterlichen Erziehungsverhalten (FEE). The FEE consists of 24 items (8 in each subscale), and assesses three parenting dimensions: paternal/maternal emotional warmth, paternal/maternal rejection and punishment, and paternal/maternal control and overprotection [14]. The 24 items consist of 4-point scales, with scales in each domain ranging from eight to 32 . Higher scores indicate high recognition for parental behaviors in each domain. Before using the measurement tool, the German questionnaire was translated into Korean by a bilingual expert fluent in both German and Korean. A second bilingual expert verified the meaning of each sentence using reverse translation. Seven healthy adolescents without CHD participated in a pilot test for validity before data collection from CHD participants was initiated. The internal reliability coefficients in the study for 2984 general subjects were $0.86,0.89$, and 0.74 for paternal/maternal emotional warmth, paternal/maternal rejection and punishment, and paternal/maternal control and over-protection, respectively [14]. The internal reliability coefficients in this study were 0.94 , 0.87 , and 0.81 for paternal/maternal emotional warmth, paternal/maternal rejection and punishment, and paternal/maternal control and over-protection, respectively.

\section{Pediatric cardiac quality of life inventory (PCQLI)}

We measured CHD adolescent HRQOL using the Pediatric Cardiac Quality of Life Inventory (PCQLI). The PCQLI is a disease-specific QOL measure for children and adolescents with congenital and acquired heart disease, designed to be self-administered within $10 \mathrm{~min}$. It is composed of 29 items and two subscales, which are disease impacts with 17 items and psychosocial area with 12 items, measured with a five point Likert scale [15]. We used the adolescent form, in which the scores can range from zero to 100, with higher scores indicating higher QOL levels for each area. Before using the PCQLI, the researchers translated the instrument from English into Korean, and a bilingual expert 
verified the meaning of each sentence using reverse translation. Subsequently, five experts (including two pediatric cardiologists, one pediatric cardiac surgeon, one pediatric nurse practitioner, and one pediatric nursing professor) evaluated and modified the items in the instrument to pertain to pediatric patients with $\mathrm{CHD}$. The reliability coefficient was 0.84 in the original study [15], 0.93 in a study of adolescents with heart disease [16], and 0.94 in the present study.

\section{Socio-demographic characteristics and health-related characteristics}

Gender, age, school, presence of siblings, having any religion, perceived economic status, and parent education levels were assigned as socio-demographic characteristics. Diagnosis and NYHA class were assigned as healthrelated characteristics. Diagnosis was classified as simple, moderately severe, and great complexity [17].

\section{Ethical considerations}

Ethics approval for this human-subject database research was obtained from the institutional review board (IRB No. 2013-0597) of the hospital where this study was conducted.

\section{Data analysis}

The data was analyzed using SPSS 21.0. Descriptive statistics were used to define participants' sociodemographic characteristics, health-related characteristics, perceived parental rearing behaviors, and HRQOL. Student's $t$-test and analysis of variance (ANOVA) were conducted to identify HRQOL differences according to general and health-related characteristics. Correlation analysis was used to investigate the relationship between perceived parental rearing behaviors and HRQOL. We used stepwise multiple linear regression analysis to explore the relationship among health conditions, familial factors and HRQOL for CHD adolescents. We tested independent variables including the presence of siblings, economic status, NYHA functional class, emotional warmth and control/overprotection of parents. These were significant variables associated with HRQOL in previous analyses.

\section{Results}

General and health-related characteristics of the participants Participant demographics and disease-related characteristics are shown in Table 1. Among all participants, 65 (66.3\%) were male with mean age of 15.18. A total of 53 participants $(54.1 \%)$ were middle school students, 37 (37.8\%) were high school students, and eight participants (8.2\%) were university students. Most of the participating adolescents had siblings. Only six participants (6.1\%)
Table 1 General characteristics and health-related characteristics of the participants

\begin{tabular}{|c|c|c|}
\hline Variable & & $n(\%)$ or $\mathrm{M} \pm \mathrm{SD}$ \\
\hline \multirow[t]{2}{*}{ Gender } & Male & $65(66.3)$ \\
\hline & Female & $33(33.7)$ \\
\hline Age & & $15.18 \pm 1.86$ \\
\hline \multirow[t]{3}{*}{ School attendance } & $\leq$ Middle & $53(54.1)$ \\
\hline & High & $37(37.8)$ \\
\hline & College & $8(8.2)$ \\
\hline \multirow[t]{2}{*}{ Presence of sibling } & Yes & $92(93.9)$ \\
\hline & No & $6(6.1)$ \\
\hline \multirow[t]{2}{*}{ Having any religion } & Yes & $45(45.9)$ \\
\hline & No & $53(54.1)$ \\
\hline \multirow[t]{2}{*}{ Living with } & Parent & 93(94.9) \\
\hline & single & $5(5.1)$ \\
\hline \multirow[t]{3}{*}{ Father's education level } & $<$ High school & $4(4.1)$ \\
\hline & High school & $29(29.6)$ \\
\hline & College or beyond & $65(66.3)$ \\
\hline \multirow[t]{3}{*}{ Mother's education level } & $<$ High school & $4(4.1)$ \\
\hline & High school & $45(45.9)$ \\
\hline & College or beyond & $49(50.0)$ \\
\hline \multirow[t]{3}{*}{ Perceived economic status } & Good & $5(5.1)$ \\
\hline & Average & $81(82.7)$ \\
\hline & $\mathrm{Bad}$ & $12(12.2)$ \\
\hline \multirow[t]{3}{*}{ Diagnosis } & Simple & $23(23.5)$ \\
\hline & Moderate severity & $25(25.5)$ \\
\hline & Great complexity & $50(51.0)$ \\
\hline \multirow[t]{3}{*}{ NYHA } & I & $67(68.4)$ \\
\hline & $\|$ & $27(27.6)$ \\
\hline & III & $4(4.1)$ \\
\hline
\end{tabular}

$N=98$

were only children. Among the participants' parents, 65 (66.3\%) fathers and 49 (50\%) mothers had a universitylevel education. A total of 81 participants $(82.7 \%)$ were self-described as having above average economic status. Disease complexity was classified in three categories [17], and 50 participants (51\%) had greatly complex CHD. In addition, 67 participants (68.4\%) were classified as New York Heart Association (NYHA) functional class I, and four participants (4.1\%) were reported to have severe dyspnea in minimal activity (allowing for diseaserelated symptoms).

\section{HRQOL for adolescents with CHD according to general and health-related characteristics}

The mean HRQOL score (SD) was 79.50 (15.37), and ranged from 28.6 to 100 . HRQOL was significantly related to the presence of siblings (80.57 vs. 63.06, $p=0.01$ ), 
perceived economic status $(87.07$ vs. 80.69 vs. 68.34 , $p=0.02)$, and NYHA functional class (83.42 vs. 73.71 vs. 52.93, $p=0.00$ ) (Table 2).

\section{Correlations between perceived parental rearing behaviors and HRQOL}

Participant HRQOL was related to emotional warmth $(r=0.22, p=0.03)$ and control/overprotection $(r=-0.20$, $p=0.04)$ of fathers, and emotional warmth $(r=0.23$, $p=0.03)$ and control/overprotection $(r=-0.22, p=0.03)$ of mothers, which were sub-factors of parental rearing behaviors for both fathers and mothers (Table 3).

Health condition and familial influence on HRQOL as assessed by multiple regression analysis

In order to explore health condition and familial influence on HRQOL among adolescents with CHD, stepwise multiple linear regression analysis was performed. Our results indicated that NYHA class (Adj $\mathrm{R}^{2}=.186, p=.000$ ), presence of siblings (Adj $\mathrm{R}^{2}=.240, p=.010$ ), and mother's emotional warmth (Adj $\mathrm{R}^{2}=.265, p=.043$ ) significantly affected CHD adolescent HRQOL and the explanatory power from the three variables was $26.5 \%$ (Table 4 ).

\section{Discussion}

The mean score of HRQOL measured using PCQLI in this study was 79.50. In comparison with the HRQOL of adolescents with CHD in Westerns countries, the mean score of HRQOL in this study was similar to those in other studies using PCQLI. For example, the mean score (SD) of PCQLI for 781 adolescents with CHD in US was 79.7 (15.0) [16], and that for 673 adolescents with CHD from US and UK

Table $2 \mathrm{HRQOL}$ according to general characteristics and health-related characteristics

\begin{tabular}{|c|c|c|c|c|c|}
\hline \multirow[t]{2}{*}{ Variable } & & \multicolumn{4}{|c|}{ HRQOL } \\
\hline & & Mean & SD & t or F & $\mathrm{p}$ \\
\hline \multirow[t]{2}{*}{ Gender } & Male & 79.33 & 16.77 & -.15 & .88 \\
\hline & Female & 79.83 & 12.39 & & \\
\hline \multirow[t]{3}{*}{ School attendance } & $\leq$ Middle & 80.17 & 14.31 & 1.13 & .33 \\
\hline & High & 80.23 & 15.56 & & \\
\hline & College & 71.69 & 20.76 & & \\
\hline \multirow[t]{2}{*}{ Presence of sibling } & Yes & 80.57 & 14.85 & -2.80 & .01 \\
\hline & No & 63.06 & 14.91 & & \\
\hline \multirow[t]{2}{*}{ Having any religion } & Yes & 79.24 & 17.69 & -.15 & .30 \\
\hline & No & 79.92 & 13.25 & & \\
\hline \multirow[t]{2}{*}{ Living with } & Parent & 79.94 & 14.95 & -1.24 & .22 \\
\hline & single & 71.25 & 22.27 & & \\
\hline \multirow[t]{3}{*}{ Father's education level } & $<$ High school & 77.41 & 28.94 & .28 & .76 \\
\hline & High school & 77.94 & 17.04 & & \\
\hline & College or beyond & 80.33 & 13.77 & & \\
\hline \multirow[t]{3}{*}{ Mother's education level } & $<$ High school & 74.95 & 28.20 & .36 & .70 \\
\hline & High school & 80.68 & 16.09 & & \\
\hline & College or beyond & 78.79 & 13.66 & & \\
\hline \multirow{3}{*}{$\begin{array}{l}\text { Perceived } \\
\text { economic status }\end{array}$} & Good & 87.07 & 9.55 & 4.29 & .02 \\
\hline & Average & 80.69 & 13.74 & & \\
\hline & Bad & 68.34 & 22.47 & & \\
\hline \multirow[t]{3}{*}{ Diagnosis } & Simple & 83.25 & 14.88 & 1.39 & .26 \\
\hline & Moderate severity & 80.82 & 10.35 & & \\
\hline & Great complexity & 77.12 & 17.39 & & \\
\hline \multirow[t]{3}{*}{ NYHA } & 1 & 83.42 & 12.43 & 12.46 & .00 \\
\hline & $\|$ & 73.71 & 16.08 & & \\
\hline & III & 52.93 & 20.21 & & \\
\hline Total & & 79.50 & 15.37 & & \\
\hline
\end{tabular}


Table 3 Correlational relationships between perceived parenting style and HRQOL

\begin{tabular}{|c|c|c|c|c|c|c|}
\hline \multirow[t]{2}{*}{ Variables } & \multicolumn{3}{|l|}{ Father } & \multicolumn{3}{|l|}{ Mother } \\
\hline & Emotional Warmth & $\begin{array}{l}\text { Rejection/ } \\
\text { punishment }\end{array}$ & $\begin{array}{l}\text { Control/ } \\
\text { overprotection }\end{array}$ & Emotional Warmth & $\begin{array}{l}\text { Rejection/ } \\
\text { punishment }\end{array}$ & $\begin{array}{l}\text { Control/ } \\
\text { overprotection }\end{array}$ \\
\hline$\overline{\mathrm{HRQOL}}$ & $.22^{*}$ & -.19 & $-.20^{*}$ & $.23^{*}$ & -.11 & $-.22^{*}$ \\
\hline
\end{tabular}

was 76.0 (16. 0) [18]. This result indicates that HRQOL of Korean adolescents with CHD was similar to that in Western countries.

This study showed that mother's emotional warmth positively associated with the HRQOL for CHD adolescents. Consistent with this study, results from a study by Rassart et al. [19] indicated that perceptions of parental acceptance were positively correlated with CHD adolescent self-esteem. Warm and accepting parent-adolescent relationships contributed to the well-being of children and adolescents at risk [20], and were related to higher levels of QOL and fewer psychological symptoms in adolescents with chronic diseases [21]. Also, The QOL of adolescents suffering from inflammatory bowel disease positively correlated with the warm parental style [22] while the QOL of adolescents with diabetes type 1 was positively associated with mindful parental style [23]. Our findings indicate that emotional warmth is positively associated with the HRQOL of adolescents with CHD. Therefore, health providers need to inform parents of the advantages of demonstrating these positive parental behaviors.

This study also found the presence of siblings was positively associated with the HRQOL of adolescents with CHD. This finding is consistent with the study for the siblings of people diagnosed with a mental disorder that showed siblings mature faster and support their family [24]. Siblings played a significant role as emotional support and advocates [25] thus, siblings could facilitate adaptation and enhance the resilience of adolescents with disease [25]. The presence of siblings may be vital in helping to maintain a sense of security and emotional continuity, as well as self-identity [26]. Therefore, further studies on the development of programs that include siblings as well as parents for adolescents with $\mathrm{CHD}$ are needed.

Table 4 Factors related to HRQOL

\begin{tabular}{lllll}
\hline Variable & B & $\beta$ & AdjR-sq & $P$ \\
\hline Constant & 58.634 & & & \\
NYHA class & -11.391 & -.416 & .186 & .000 \\
Presence of sibling & 14.681 & .230 & .240 & .010 \\
Mother's emotional warmth & 0.482 & .180 & .265 & .043 \\
\hline$N=98$ & & & & \\
$\mathrm{~F}=12.641$ & & & &
\end{tabular}

According to this study's results, the HRQOL for adolescents with CHD did not differ according to CHD severity. That is, disease severity was a poor HRQOL predictor [27, 28]. However, the HRQOL for adolescents with CHD in this study was significantly different depending on their NYHA functional class. Consistent with this finding, Schoormans et al. [29] used a TNO/ AZL Adult Quality of Life-CHD (TAAQOL-CHD) subscale and showed that perceived HRQOL in CHD patients was partially associated with their NYHA functional class. In contrast to this finding, a study by Bang et al. [30] suggested that QOL levels, depression, and anxiety in CHD patients did not differ significantly according to their NYHA class. The NYHA class for participants in that study, however, consisted of only classes I and II. Accordingly, the effects on QOL by NYHA class need to include patients in classes I, II, and III for more robust results. Also, Bang et al. [30] used the short version of the World Health Organization QOL (WHOQOL-BREF) to evaluate QOL. Evaluation of HRQOL using WHOQOL-BREF is difficult because WHOQOL is generic measures of QOL, and may not capture the nuances of QOL with a chronic disease. Therefore, future research is needed to assess QOL using a scale for CHD-related HRQOL.

The explanatory power from NYHA class, presence of siblings, and mother's emotional warmth in this study was $26.5 \%$, which showed the low level of explanation. This indicates that other variables besides our results might affect to HRQOL of adolescents with CHD. Researchers mentioned that illness perception [31], emotional distress [32] and social support [32] were also able to be factors that influenced HRQOL of adolescents with CHD. In addition, gender, school and perceived economic status were excluded as related factors on HRQOL of adolescents with CHD in this study. Aper et al. [4] insisted that gender was not associated with HRQOL in their study for QOL of adults with CHD, whereas other researchers mentioned that gender was an influential factor on HRQOL in the studies for adult patients with heart disease $[31,32]$. With regard to economic statue, Eslami et al. [32] described that economic status was associated with HRQOL of adults with CHD, which is not inconsistent with our study. However, the majority of studies for examining the relation between QOL and socio-demographic variables were for 
adults with CHD. Therefore, future research is needed to investigate influential factors of HRQOL in adolescent with CHD including illness perception, emotional distress, peer-support, and so on.

\section{Limitations}

This study has several limitations. First, participants came from a single medical center in Korea and parental rearing behaviors of Korean cannot represent all parents, possibly limiting the generalizability of these findings. Second, there is potential bias from the translation of the scales, such as FEE and PCQLI, to Korean without consideration of cultural differences. Third, data collecting period was only summer time which can affect HRQOL, possibly limiting the representativeness. Forth, it is difficult to describe the factors affecting the HRQOL of adolescents with CHD, because this study was designed as a cross-sectional study; therefore, follow-up research designed by a longitudinal study is needed. Lastly, the number of participants without a sibling was six and the number of participants with NYHA class III was four, which are small sample sizes; therefore, a larger follow-up study on the presence of siblings and NYHA class III participants is needed.

\section{Conclusions}

Our results indicate that NYHA class, presence of siblings, and mothers' emotional warmth are predictors of HRQOL for adolescents with CHD. To improve the CHD adolescent HRQOL, emotionally warm parental rearing behaviors, the presence of siblings, and lower level of NYHA class are important familial factors. Therefore, it is important for healthcare providers to develop greater sensitivity to familial factors as well as the exigencies of the CHD health condition.

\section{Abbreviations \\ CHD: Congenital heart disease; FEE: Parental rearing behaviors; HRQOL: Health-related quality of life; NYHA: NYHA New York Heart Association; PCQLI: Pediatric cardiac quality of life inventory; TAAQOL- CHD: TNO/AZL Adult Quality of Life-CHD; WHOQOL-BREF: World Health Organization QOL short version}

\section{Acknowledgements}

Not applicable

\section{Funding}

This research was supported by Basic Science Research Program through the National Research Foundation of Korea (NRF) funded by the Ministry of Education, Science and Technology (NRF-2012R1A1A3007989/NRF-2016R1D1A1B01011002).

\section{Availability of data and materials}

The datasets generated and/or analysed during the current study are available from the corresponding author on reasonable request.

\section{Authors' contributions}

YI led the acquisition of data and drafted manuscripts. SL conceived the study, contributed to interpretation of data and manuscripts. TJ led the acquisition of data and contributed to the study design. All authors read and approved the final manuscript.

\section{Ethics approval and consent to participate}

The authors assert that all the procedures contributing to this work comply with the ethical standards of the relevant national guidelines on human experimentation and with the Helsinki declaration, and have been approved by the institutional ethics committees (IRB No. 2013-0597). Participants took part in the present study after providing written informed consent.

\section{Consent for publication}

Not applicable

\section{Competing interests}

The authors declare that they have no competing interests.

\section{Publisher's Note}

Springer Nature remains neutral with regard to jurisdictional claims in published maps and institutional affiliations.

\section{Author details}

'Seoul Women's College of Nursing Seoul, 38, Ganhodae-ro, Seodaemun-gu, Seoul 03617, South Korea. 'Division of Pediatric Cardiac Surgery, University of Ulsan College of Medicine, Asan Medical Center, 88, Olympic-ro 43-gil, Songpa-gu, Seoul 05505, South Korea. ${ }^{3}$ College of Nursing, the Catholic University of Korea, 222 Banpo-daero, Seocho-gu, Seoul 06591, South Korea.

Received: 22 August 2017 Accepted: 4 January 2018

Published online: 10 January 2018

\section{References}

1. Wray J, Brown K, Franklin R, Cassedy A, Marino BS. Assessing the generalisability of the pediatric cardiac quality of life inventory in the United Kingdom. Cardiol Young. 2014;24(2):220-8.

2. Moons P, Bovijn L, Budts W, Belmans A, Gewillig M. Temporal trends in survival to adulthood among patients born with congenital heart disease from 1970 to 1992 in Belgium. Circulation. 2010;122(22):2264-72.

3. Park JH, Park SW, Lee JY, Lee SW, Shin YH, Lee SH. Survival rates of patients with congenital heart disease. Korean Soc Matern Child Health Conf. 2003;2:81-2.

4. Apers S, Kovacs AH, Luyckx K, Thomet C, Budts W, Enomoto J, et al. Quality of life of adults with congenital heart disease in 15 countries: evaluating country-specific characteristics. J Am Coll Cardiol. 2016;67:2237-45.

5. Bratt EL, Luyckx K, Goossens E, Budts W, Moons P. Patient-reported health in young people with congenital heart disease transitioning to adulthood. J Adolesc Health. 2015;57(6):658-65.

6. Bertoletti J, Marx GC, Hattge SP, Pellanda LC. Health-related quality of life in adolescents with congenital heart disease. Cardiol Young. 2015;25(3):526-32

7. Chiang YT, Chen CW, Su WJ, Wang JK, Lu CW, Li YF, et al. Between invisible defects and visible impact: the life experiences of adolescents and young adults with congenital heart disease. J Adv Nurs. 2015;71(3):599-608.

8. Fteropoulli T, Stygall J, Cullen S, Deanfield J, Newman SP. Quality of life of adult congenital heart disease patients: a systematic review of the literature. Cardiol Young. 2013;23:473-85.

9. Yoon H, Lee MK. Quality of life of adults with congenital heart disease: a comparison with healthy controls. Korean J Health Promot. 2009;9(1):10-7. http://uci.or.kr/G704-001517.2009.9.1.004

10. Eiser $C$, Morse R. The measurement of quality of life in children: past and future perspectives. J Dev Behav Pediatr. 2001;22(4):248-56.

11. Naughton MJ, Shumaker SA. The case for domains of function in quality of life assessment. Qual Life Res. 2003;12(Suppl 1):73-80.

12. Schenker R, Parush S, Rosenbaum P, Rigbi A, Yochman A. Is a family-centred initiative a family-centered service? A case of a conductive education setting for children with cerebral palsy. Child Care Health Dev. 2016;42(6):909-17.

13. Faul F, Erdfelder E, Lang AG, Buchner A. G*power 3: a flexible statistical power analysis program for the social, behavioral, and biomedical sciences. Behav Res Methods. 2007;39:175-91.

14. Petrowski K, Berth H, Schmidt S, Schumacher J, Hinz A, Brahler E. The assessment of recalled parental rearing behavior and its relationship to life satisfaction and interpersonal problems: a general population study. BMC Med Res Methodol. 2009;9:17.

15. Marino BS, Shera D, Wernovsky G, Tomlinson RS, Aguirre A, Gallagher M, et al. The development of the pediatric cardiac quality of life inventory: a quality of life measure for children and adolescents with heart disease. Qual Life Res. 2008;17(4):613-26. 
16. Marino BS, Drotar D, Cassedy A, Davis R, Tomlinson RS, Mellion K, et al. External validity of the pediatric cardiac quality of life inventory. Qual Life Res. 2011;20(2):205-14.

17. Warnes CA, Liberthson R, Danielson GK, Dore A, Harris L, Hoffman Jl, et al. Task force 1: the changing profile of congenital heart disease in adult life. J Am Coll Cardiol. 2001;37:1170-5.

18. O'Connor AM, Wray J, Tomlinson RS, Cassedy A, Jacobs JP, Jenkins KJ, et al. Impact of surgical complexity on health-related quality of life in congenital heart diseas surgical survivors. J Am Heart Assoc. 2016;5(7):e001234.

19. Rassart J, Luyckx K, Goossens E, Apers S, Moons P. i-DETACH investigators. A closer look at the developmental interplay between parenting and perceived health in adolescents with congenital heart disease. J Behav Med. 2014;37(6):1202-14.

20. Masten S, Tellegen A. Resilience in developmental psychopathology: contributions of the project competence longitudinal study. Dev Psychopathol. 2012;24(2):345-61.

21. Ahn JA, Lee S. Peer attachment, perceived parenting style, self-concept, and school adjustments in adolescents with chronic illness. Asian Nurs Res. 2016;10(4):300-4.

22. Jelenova D, Prasko J, Ociskova M, Latalova K, Karaskova E, Hruby R, et al. Quality of life and parental styles assessed by adolescents suffering from inflammatory bowel diseases and their parents. Neuropsychiatr Dis Treat. 2016;12:665-72.

23. Serkel-Schrama IJP, de Vries J, Nieuwesteeg AM, Pouwer F, Nyklíček I, Speight J, et al. The association of mindful parenting with glycemic control and quality of life in adolesents with type 1 diabetes: results from diabetes MILES-the Netherlands. Mindfulness. 2016;7:1227-37.

24. Sanders A, Szymanski K, Fiori K. The family roles of siblings of people diagnosed with a mental disorder: heroes and lost children. Int J Psychol. 2014;49(4):257-62.

25. Carter S, Cook J, Sutton-Boulton G, Ward V, Clarke S. Social pedagogy as a model to provide support for siblings of children with intellectual disabilities: a report of the views of the children and young people using a sibling support group. J Intellect Disabil. 2016;20(1):65-81.

26. Mota CP, Matos PM. Does sibling relationship matter to self-consept and resilience in adolescents under residential care? Child Youth Serv Rev. 2015:56:97-106.

27. Garcia Guerra G, Robertson CM, Alton GY, Joffe AR, Dinu IA, Nicholas D, et al. Quality of life 4 years after complex heart surgery in infancy. J Thorac Cardiovasc Surg. 2013;145(2):482-8

28. Lee $\mathrm{S}$, Lee J, Choi JY. The effect of a resilience improvement program for adolescents with complex congenital heart disease. Eur J Cardiovasc Nurs. 2017;16(4):290-8.

29. Schoormans D, Sprangers MAG, Budts W, Mulder BJ, Apers S, Moons P. Perceived health is partially associated with the symptomatological profile in patients with benign and severe conditions: the case of congenital heart disease. Qual Life Res. 2013;2:1295-304.

30. Bang JS, Jo S, Kim GB, Kwon BS, Bae EJ, Noh Cl, et al. The mental health and quality of life of adult patients with congenital heart diease. Int J Cardiol. 2013;179:49-53.

31. Schoormans D, Mulder BJM, van Melle JP, Pieper PG, van Dijk AP, Sieswerda GT, et al. Illness perception of adults with congenital heart disease and their predictive value for quality of life two year later. Eur J Cardiovasc Nurs. 2014;13(1):86-94.

32. Eslami B, Macassa G, Sundin Ö, Khankeh HR, Soares JJ. Quality of life and life satisfaction among adults with without congenital heart disease in a developing country. Eur J Prev Cardiol. 2015;22(2):169-79.

\section{Submit your next manuscript to BioMed Central and we will help you at every step:}

- We accept pre-submission inquiries

- Our selector tool helps you to find the most relevant journal

- We provide round the clock customer support

- Convenient online submission

- Thorough peer review

- Inclusion in PubMed and all major indexing services

- Maximum visibility for your research

Submit your manuscript at www.biomedcentral.com/submit
Biomed Central 